\title{
Phytochemical Screening and Antimicrobial Evaluation of Syzygium aromaticum Extract and Essential oil
}

\author{
Simiat Olanike Jimoh ${ }^{1 *}$, Lateefah Adelanke Arowolo ${ }^{1}$ and Kazeem Adelani Alabi ${ }^{2}$ \\ ${ }^{1}$ Microbiology Unit, Department of Biological Sciences, College of Natural and Applied \\ Sciences, Fountain University Osogbo, Osun State, Nigeria \\ ${ }^{2}$ Industrial and Environmental Chemistry Unit, Department of Chemical Sciences, College of \\ Natural and Applied Sciences, Fountain University Osogbo, Osun State, Nigeria \\ *Corresponding author
}

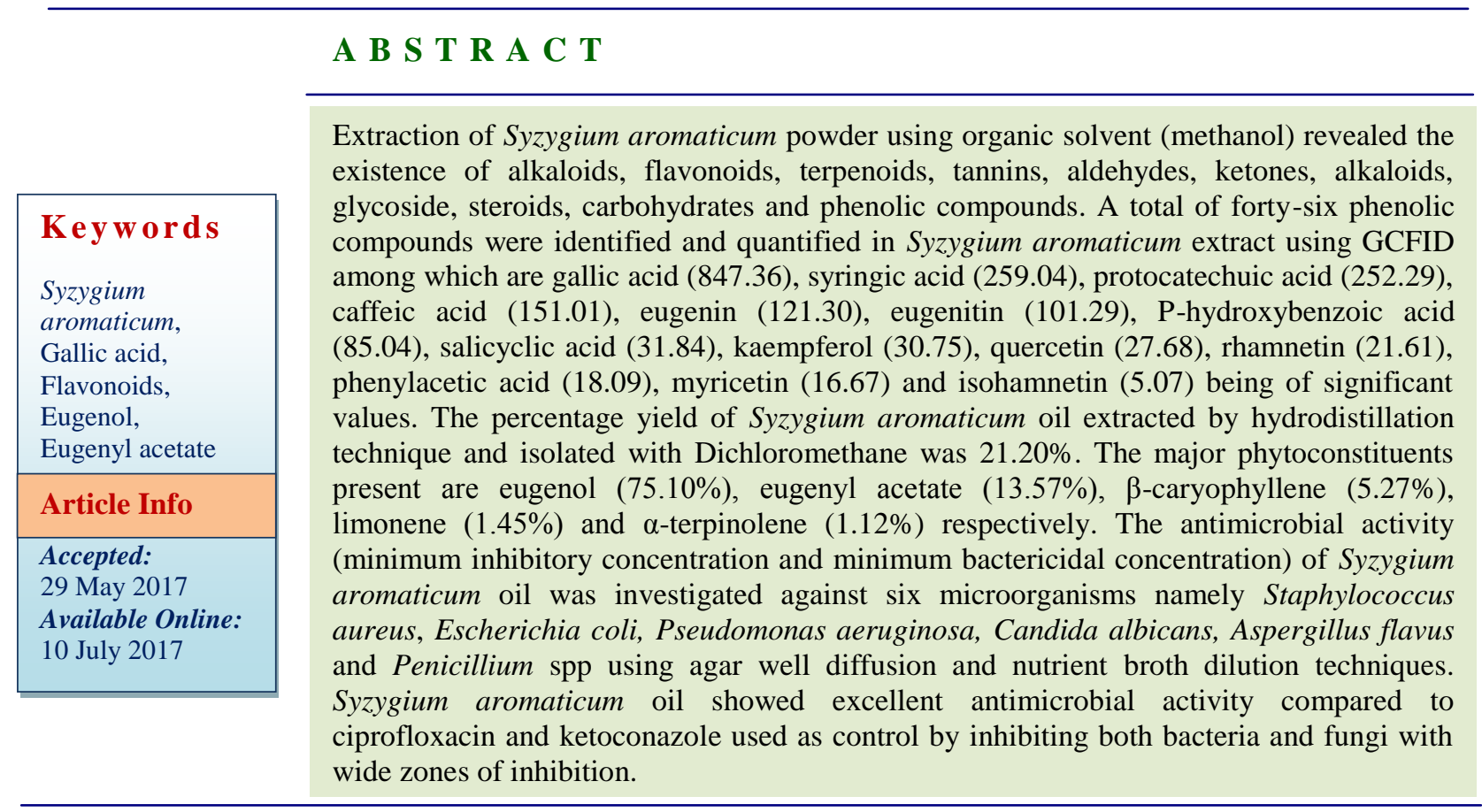

\section{Introduction}

Spices and herbs have been used for thousands of centuries by many continents to enhance the flavor and aroma of foods; preserving foods and for their medicinal value. Spices are aromatic plant products which are frequently used to enhance food palatability. Most spices were originally indigenous to the tropics eg. cinnamon, pepper, clove and nutmeg (Viuda-Martos et al., 2007). Syzygium aromaticum (Clove bud) is one of the most ancient and valuable spices of the Orient (Chaieb et al., 2007) which are used as a carminative to increase hydrochloric acid in the stomach and to improve peristalsis.

Essential oil compounds are fat soluble thus possess the ability to permeate the membranes of the skin before being captured by the microcirculation and drained into the systemic circulation which reaches all targets organs (Adorjan and Buchbauer, 2010). Due to their 
molecular structures (presence of olefenic double bonds and functional groups such as hydroxyl, aldehyde, ester); essential oils are readily oxidizable by light, heat and air. (Skold et al., 2008).

The essential oil extracted from the dried flower buds of cloves is used for acne, warts, scars and parasites. Research has shown that clove oil is an effective mosquito repellent (Trongtokit et al., 2005). Culinary spices and herbs contain a wide variety of active phytochemicals including flavonoids, terpenes, polyphenols, curcumins, coumarins (Fabio et al., 2003). The aim of this research is to determine the phytochemical constituents and antimicrobial effect of Syzygium aromaticum oil and crude extract.

\section{Materials and Methods}

\section{Chemicals}

The phenolic acids standards and 1, 1diphenyl-2-picrylhydrazyl (DPPH-90\% purity) were purchased from Aldrich (Aldrich Chemical Co., Milwaukee, WI) and SigmaAldrich Co., St. Louis, MO, USA respectively.

\section{Growth condition of test organisms}

Previously characterized isolates (Staphylococcus aureus, Escherichia coli, Pseudomonas aeruginosa, Candida albicans, Aspergillus flavus and Penicillium) obtained from Medical Microbiology Laboratory of Fountain University were used. Bacterial isolates were subcultured on nutrient agar at $37^{\circ} \mathrm{C}$ for $24 \mathrm{~h}$ while fungal on Sabouraud Dextrose Agar at $28^{\circ} \mathrm{C}$ for 3 days respectively. All isolates were maintained at $4^{\circ} \mathrm{C}$ on Nutrient agar slope for further analysis.

\section{Pretreatment and Processing of Sample}

Syzygium aromaticum bud was procured from
Oluode market in Osogbo, Osun State, Nigeria. Damaged and spoilt buds were removed; pulverized into powdery form, filtered to remove residues and stored in an air-tight container at room temperature for further analysis. The organoleptic characteristics of the smooth powder such as color, flavor, odor and intensity of odor were observed.

\section{Preparation of Syzygium aromaticum Extract}

Syzygium aromaticum aqueous extraction was done using methanol and distilled water. Twenty five grams of Syzygium aromaticum powder was soaked in distilled water and methanol (250 ml each) separately at room temperature for 7 days. The mixtures were stirred intermittently every 18 hours by gently swirling of the flask thus slurry obtained was filtered after 7 days and crude residue was used for the analyses. The filtrate was concentrated under reduced pressure in a rotary vacuum evaporator (NYC R- 205D) at $40^{\circ} \mathrm{C}$ (Bag et al., 2009) thus; semisolid substance obtained was dried in hot air oven at $45^{\circ} \mathrm{C}$ to obtain crude extract (Jonathan and Fasidi, 2003). The crude extracts obtained were reconstituted in Dimethyl Sulfoxide (DMSO) and subjected to preliminary phytochemical screening, scavenging property and antimicrobial analysis. Confirmatory analysis was done using Gas chromatography flame ionization detector in order to identify the chemical constituents.

\section{Preliminary Phytochemical Screening of Syzygium aromaticum Extract}

Phytochemical constituents \{ such as tannins, saponins, phlobatanins, phenolics, reducing sugar, trepenoid, steroid, glycosides, alkanoids (Hager's and Wanger's tests) and flavonoids (ferric chloride, sodium chloride and lead acetate tests) $\}$ of the crude extracts 
were analyzed. Syzygium aromaticum extract (2 ml each) was utilized separately for each analysis thus formation of precipitate, color change or frothing indicates presences of the phytochemical mentioned above (Sofowora, 1993).

\section{DPPH radical scavenging assay}

The antioxidant activity of Syzygium aromaticum extracts was assayed using 2, 2diphenyl-1-picrylhydrazyl (DPPH) (Burits et al., 2000). Fifty microlitres of varying concentrations $(10-50 \%)$ of the extracts were added to $5 \mathrm{ml}$ of $0.004 \%$ methanol solution of DPPH and incubated for 30 minutes at room temperature. Absorbance was measured against quercetin at $517 \mathrm{~nm}$ using UV-Visible spectrophotometer. Thus, inhibition rate (I \%) on free radical DPPH was calculated as stated below;

Inhibition $\%(\mathrm{I} \%)=\left\{\left(\mathrm{A}_{\text {blank }}-\mathrm{A}_{\text {sample }}\right) \div \mathrm{A}_{\text {blank }}\right\}$ $\times 100$

$\mathrm{A}_{\text {blank }}=$ absorbance of the control reaction

$\mathrm{A}_{\text {sample }}=$ absorbance of the test compound

Quercetin $=$ Standard reference (blank)

\section{Confirmatory Analysis}

\section{Quantification of Phenolic Compounds Present in Syzygium aromaticum Extract}

Phenolic compounds were extracted using two- stage extraction procedures according to Kelley et al., (1994) and Provan et al., (1994). At the initial stage, 50mg of Syzygium aromaticum powder was extracted with $5 \mathrm{ml}$ of $1 \mathrm{M} \mathrm{NaOH}$ for 16 hours on a shaker at ambient temperatures. After extraction, the sample was centrifuged at $5000 \mathrm{rpm}$, rinsed with water repeatedly and supernatant obtained was heated at $90^{\circ} \mathrm{C}$ for 2 hours to release the conjugated phenolic compounds. The heated extract was cooled, titrated with
$4 \mathrm{M}$ HCI to $\mathrm{pH}<2.0$, diluted to $10 \mathrm{ml}$, with deionised water and centrifuged to remove the precipitate. During the final stage, the residue (precipitate) was extracted with $5 \mathrm{ml}$ of $4 \mathrm{M}$ $\mathrm{NaOH}$, heated to $160^{\circ} \mathrm{C}$ in Teflon and allowed to cool before filtering. The supernatant obtained was adjusted to $\mathrm{pH}<2.0$ with $4 \mathrm{M}$ $\mathrm{HCI}$ and further subjected to purification.

\section{Purification of Phenolic Compounds Present in the Extract}

An aliquot $(5-15 \mathrm{ml})$ of the supernatant was passed through a conditioned Varian Bond Elut PPL (3 ml size with $200 \mathrm{mg}$ packing) solid-phase extraction tube at $5 \mathrm{ml} / \mathrm{min}$ attached to a Visiprep (Supelco, Bellefonte, PA). The tubes were placed under a vacuum $(-60 \mathrm{kPa})$ until the resin was thoroughly dried and phenolic acids were eluted with $1 \mathrm{ml}$ of ethyl acetate into gas chromatography autosampler vials. The PPL tubes were conditioned by passing $2 \mathrm{ml}$ of ethyl acetate followed by $2 \mathrm{ml}$ water ( $\mathrm{pH}<2.0$ ).

\section{Derivatisation (Silylation) of Extract}

After extraction, $2 \mathrm{ml}$ of concentrated extract present in gas chromatography vial was derivatized by adding $20 \mu \mathrm{l}$ of bis(trimethylsilyl) trifluoroacetamide (derivatising agent) with a magnetic stirrer at $45^{\circ} \mathrm{C}$ for 10 minutes. This was done using gas chromatography (HP 6890) powered with HP Chemstation Rev.A09.01 [1206] Software, Split injection at split ratio 20:1 using Nitrogen as carrier gas, inlet temperature of $250^{\circ} \mathrm{C}$ and flame ionization detector. The oven was programmed at initial temperature of $60^{\circ} \mathrm{C}$ for 5 minutes, first ramping at $15^{\circ} \mathrm{C} / \mathrm{min}$ for 15 minutes and second ramping at $10^{\circ} \mathrm{C} / \mathrm{min}$ for 4 minutes respectively.

\section{Extraction of Syzygium aromaticum Oil}

Syzygium aromaticum oil was extracted from 
$10 \% \mathrm{w} / \mathrm{v}$ Syzygium aromaticum powder using hydro-distillation technique at $100 \mathrm{oC}$ and continuous agitation with magnetic stirrer (Schnaubelt, 2005). The essential oil was separated from the distillate by mixing with chloroform in a seperatory funnel; the lower layer (organic layer) contains Syzygium aromaticum oil and chloroform while the upper layer is the aqueous layer. Furthermore, organic layer was dried by mixing with $2 \mathrm{~g}$ of anhydrous Sodium sulfate and allowed to stand overnight. The residue was removed by decanting while the volatile chloroform was separated from the essential oil by exposure to air thus percentage yield of essential oil obtained was determined.

\section{Quantification of Syzygium aromaticum Oil}

Essential oil obtained was analyzed by Gas Chromatography-Flame Ionization Detector HP 6890 Powered with HP ChemStation Rev. A 09.01 [1206] Software in order to determine the constituent and corresponding concentration. The chromatography was done in HP 5MS column $(0.25 \mu \mathrm{m}$ interior diameter $\times 30 \mathrm{~m}$ long) with a particle size of $0.25 \mu \mathrm{m}$, at a flow rate of $1.0 \mathrm{ml} / \mathrm{min}$ using Flame Ionization Detector (FID) signal and hydrogen as the mobile phase at injection temperature of $150^{\circ} \mathrm{C}$ and $300^{\circ} \mathrm{C}$ detector temperature respectively.

\section{Antimicrobial Effectiveness of Syzygium aromaticum oil}

Antibacterial and antifungal activity of Syzygium aromaticum oil was determined using agar well diffusion method. Suspension [10 $\mu \mathrm{L}$ of cell suspension containing $1.1 \times 10^{4}$ $\mathrm{CFU} / \mathrm{mL}$ of each test organism (bacterium and fungus)] was inoculated separately on sterile Muller-Hinton agar using spread plate method. The plates were allowed to dry and a sterile cork borer of diameter $6 \mathrm{~mm}$ was used to bore wells in the agar plates (Okeke et al.,
2001). Subsequently, $50 \mu \mathrm{L}$ of the essential oil was transferred into triplicate wells; sterile DMSO $(50 \mu \mathrm{L})$ was the negative control for the assay while ciprofloxacin $(50 \mu \mathrm{L})$ and ketoconazole $(50 \mu \mathrm{L})$ served as positive controls for antibacterial and antifungal assays respectively. The plates were incubated after 1 hour at $37^{\circ} \mathrm{C}$ for 24 hours for bacteria growth (Khokra et al., 2008) and $28^{\circ} \mathrm{C}$ for fungi (Fiori et al., 2000). Zones of inhibition were recorded to the nearest diameter in millimeter according to Moreira et al., (2007).

\section{Minimum Inhibitory Concentration (MIC)} and Minimum Bactericidal Concentration (MBC) of Syzygium aromaticum Oil

The MIC of Syzygium aromaticum oil for bacterial strains was determined by broth microdilution assay (Hammer et al., 1996). Overnight cultures were prepared by inoculating Mueller hinton broth $(2 \mathrm{ml})$ and incubating at $37^{\circ} \mathrm{C}$ for 24 hours. After incubation, culture broths were adjusted to McFarland standard number 1 by diluting with sterile distilled water to obtain a concentration of $1.1 \times 10^{4} \mathrm{CFU} / \mathrm{mL}$. Serial dilution of the culture broth with varying concentrations $(1,3,5,7$ and $9 \mu \mathrm{l} / \mathrm{ml})$ of clove oil was prepared separately while sterile DMSO and ciprofloxacin served as negative and positive controls. MIC for fungal strains was determined using agar dilution method. Saboraud dextrose agar plates were prepared separately with increasing concentration of Syzygium aromaticum oil from $1 \mu \mathrm{l} / \mathrm{ml}$ to 9 $\mu 1 / \mathrm{ml}(\mathrm{v} / \mathrm{v})$ in intervals and dissolved with sterile DMSO (20\%) in the medium; inoculated with $10 \mu \mathrm{l}$ of fungal suspension $\left(1.1 \times 10^{4} \mathrm{CFU} / \mathrm{mL}\right)$ and incubated at $28^{\circ} \mathrm{C}$ for 3 days. Sterile DMSO and ketoconazole served as negative and positive controls respectively. Zones of inhibition were measured, thus agar plate with lowest concentration of Syzygium aromaticum oil 
inhibiting visible growth of bacterial and fungal after incubation period was regarded as the MIC (Lee et al., 2007). Ten microliters of the invisible culture broth were inoculated onto Mueller Hinton agar and incubated at $37^{\circ} \mathrm{C}$ for 24 hours. MBCs were determined from the lowest concentration of clove oil that inhibited growth on Mueller Hinton agar.

\section{Results and Discussion}

\section{Organoleptic Characteristics of Syzygium aromaticum}

The organoleptic characteristics of Syzygium aromaticum powder such as color, flavor, odor, and intensity of odor observed are reddish- brown, burning and spicy, strong aroma and pungent while the characteristics of the essential oil include color (colorless to light yellow, becoming brownish when aging), appearance (slightly murky), odor (spices cloves like), intensity of color (strong, pungent) and flavor (warm, almost burning spicy flavor) respectively.

\section{Preliminary Phytochemical Screening of Syzygium aromaticum Extract}

Based on the preliminary screening, phlobatannins, reducing sugar and steroids were absent in methanolic extract of Syzygium aromaticum but present in distilled water extract. Color change such as dark green color indicates presence of tannins and phenolics, reddish brown interface (terpenoids and glycosides), greenish (steroids), yellow to colorless (flavonoids) respctively. Formation of precipitate such as red precipitate indicates presences of phlobatannins or reducing sugar, yellow or reddish brown (alkanoids) and yellow precipitate (flavonoids) while persistence of frothing indicates presences of saponins (Table I).

\section{Quantification of Phenolic compounds Present in Syzygium aromaticum Extract}

A total of forty-six phenolic compounds were identified and quantified in Syzygium aromaticum powder using GCFID (Table II). These include gallic acid (847.36), syringic acid (259.04), protocatechuic acid (252.29), caffeic acid (151.01), eugenin (121.30), eugenitin (101.29), P-hydroxybenzoic acid (85.04), salicyclic acid (31.84), kaempferol (30.75), quercetin (27.68), rhamnetin (21.61), phenylacetic acid (18.09), myricetin (16.67) and isohamnetin (5.07) being of significant values.

\section{Quantification of Syzygium aromaticum oil using GC-FID}

Percentage yield of Syzygium aromaticum oil obtained was $21.20 \%$. A total of thirty nine compounds representing $100 \%$ of the total essential oil were analyzed and concentrations of the main components are eugenol (75.10\%), acetyleugenol (13.57\%), Beta caryophyllene $(5.27 \%)$, limonene $(1.45 \%)$ and alpha-terpinolene $(1.12 \%)$ respectively (Table III).

\section{Antioxidant Activity of Syzygium aromaticum extracts}

Distilled water extract of Syzygium aromaticum has lower inhibition i.e scavenging effect on DPPH compared to the methanolic extract and reference antioxidant (quercetin) (Figure I).

\section{Antibacterial and Antifungal Activity of Syzygium aromaticum Oil}

Syzygium aromaticum oil has high inhibitory effect on bacterial isolates ( $S$. aureus, E. coli and $P$. aeruginosa) with zones of inhibition of $30 \pm 0.02 \mathrm{~mm}, 28 \pm 0.11 \mathrm{~mm}$ and $21 \pm 0.05 \mathrm{~mm}$ and fungal isolates (C. albicans, A. flavus and Penicillium species) with $44 \pm 0.03 \mathrm{~mm}$, $51 \pm 0.13 \mathrm{~mm}, 47 \pm 0.11 \mathrm{~mm}$ zones of inhibition respectively compared to ciprofloxacin $(14 \pm 0.06 \mathrm{~mm}, 12 \pm 0.01 \mathrm{~mm}$ and $13 \pm 0.02 \mathrm{~mm})$ and ketoconazole $(14 \pm 0.13 \mathrm{~mm}, 10 \pm 0.18 \mathrm{~mm}$ and $11 \pm 0.08 \mathrm{~mm}$ ). 
Table.1 Preliminary Phytochemical Screening of Syzygium aromaticum Extracts

\begin{tabular}{lll}
\hline Parameters & Distilled Water Extract & Methanolic Extract \\
\hline Tannins & Present & Present \\
Saponins & Present & Present \\
Phlobatannins & Present & Absent \\
Phenolic compounds & Present & Present \\
Reducing sugar & Present & Absent \\
Terpenoids & Present & Present \\
Steroids & Present & Absent \\
Glucosides & Present & Present \\
Alkaloids & & \\
Hager's test & Present & Absent \\
Wagner's test & Present & Present \\
Flavonoids & & \\
Sodium hydroxide test & Absent & Absent \\
Ferric chloride test & Present & Present \\
Lead acetate test & Absent & Absent \\
\hline
\end{tabular}

Fig.1 DPPH scavenging effect of Syzygium aromaticum extracts

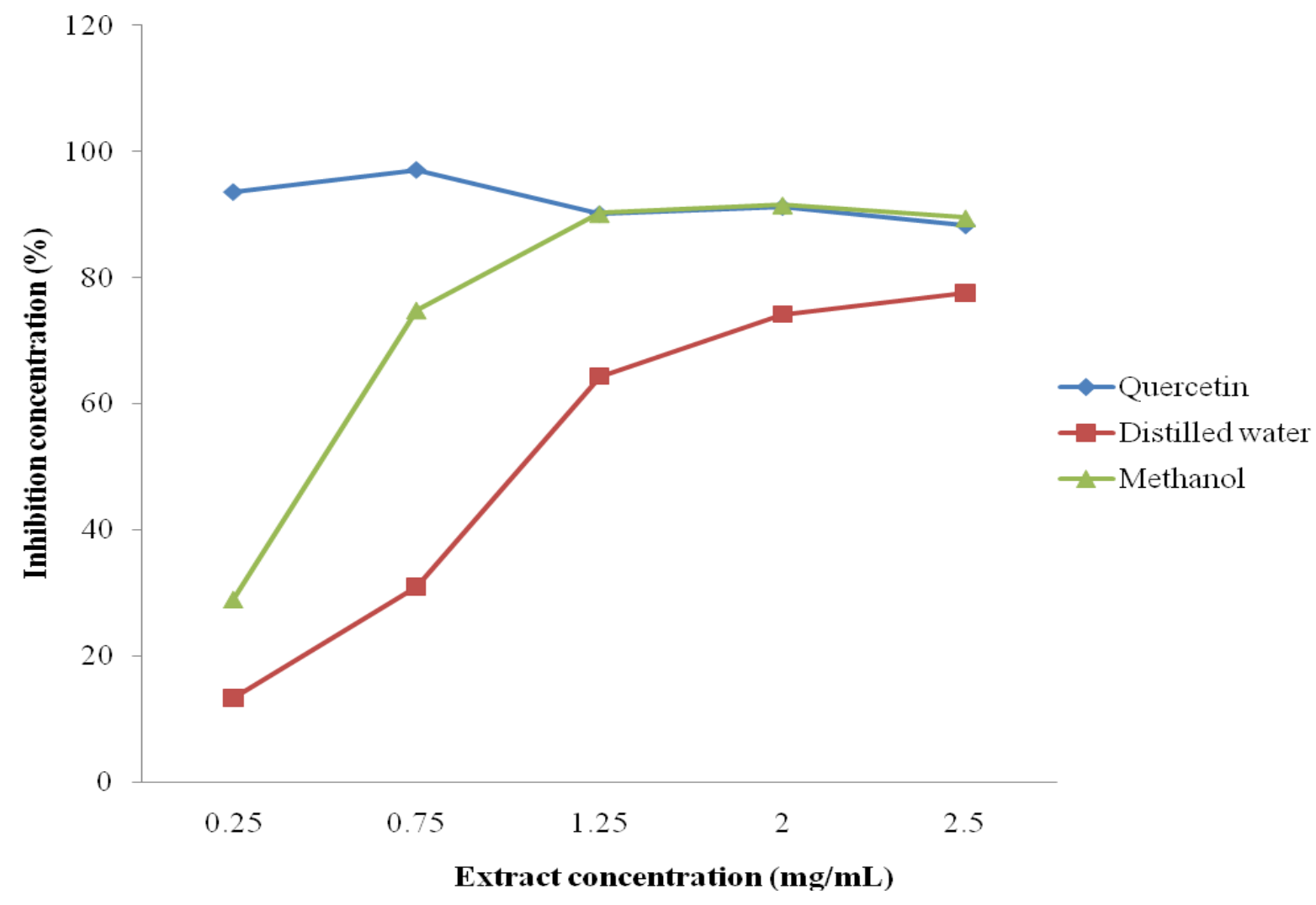


Table.2 Phenolic Compound Present in Syzygium aromaticum Extract

\begin{tabular}{|c|c|c|c|c|}
\hline Ret Time [min] & Area $\left[\mathrm{pA}^{*} \mathrm{~s}\right]$ & Amount/Area & Amount $[\mathrm{mg} / 100 \mathrm{~g}]$ & Compound \\
\hline 7.057 & 38.02240 & $7.96178 \mathrm{e}-6$ & $3.02726 \mathrm{e}-4$ & Catechin \\
\hline 7.521 & 8.93904 & $7.96178 \mathrm{e}-6$ & 7.11707e-5 & Guaiacol \\
\hline 7.915 & 189.57533 & $7.96178 \mathrm{e}-6$ & $1.50936 \mathrm{e}-3$ & Phloroglucinol \\
\hline 8.291 & 15.71195 & 1.15101 & 18.08466 & Phenylacetic acid \\
\hline 8.513 & 33.36761 & $9.54198 \mathrm{e}-1$ & 31.83932 & Salicyclic acid \\
\hline 8.893 & 59.06726 & $7.96178 \mathrm{e}-6$ & $4.70231 \mathrm{e}-4$ & Cinnamic acid \\
\hline 9.321 & 42.55415 & $7.96178 \mathrm{e}-6$ & $3.38807 \mathrm{e}-4$ & Coumarin \\
\hline 9.731 & 96.59180 & $6.70241 \mathrm{e}-3$ & $6.47398 \mathrm{e}-1$ & Carvacrol \\
\hline 10.174 & 28.37762 & $7.96178 \mathrm{e}-6$ & $2.25936 \mathrm{e}-4$ & Gentisic acid \\
\hline 10.639 & 60.96240 & 4.13844 & 252.28940 & Protocatechuic acid \\
\hline 11.054 & 34.66746 & $1.20773 \mathrm{e}-2$ & $4.18689 \mathrm{e}-1$ & P-coumaric acid \\
\hline 11.349 & 78.53786 & $1.18596 \mathrm{e}-2$ & $9.31426 \mathrm{e}-1$ & Vanillic acid \\
\hline 11.663 & 50.40628 & $7.96178 \mathrm{e}-6$ & $4.01324 \mathrm{e}-4$ & o-coumaric acid \\
\hline 12.818 & 35.51277 & 2.39464 & 85.04016 & P-hydroxybenzoic acid \\
\hline 13.416 & 62.43334 & 13.57220 & 847.35806 & Gallic acid \\
\hline 13.736 & 96.05247 & 1.57213 & 151.00691 & Caffeic acid \\
\hline 14.915 & 50.82818 & $3.61899 \mathrm{e}-3$ & $1.83947 \mathrm{e}-1$ & Ferulic acid \\
\hline 15.307 & 39.70530 & 6.52401 & 259.03770 & Syringic acid \\
\hline 15.469 & 65.69872 & $1.61463 \mathrm{e}-3$ & $1.06079 \mathrm{e}-1$ & Piperic acid \\
\hline 16.034 & 180.49785 & $6.72010 \mathrm{e}-1$ & 121.29645 & Eugenin \\
\hline 16.243 & 83.44453 & $7.18370 \mathrm{e}-4$ & $5.99440 \mathrm{e}-2$ & Sinapinic acid \\
\hline 16.668 & 136.01073 & $4.03226 \mathrm{e}-4$ & $5.48430 \mathrm{e}-2$ & Daidzein \\
\hline 18.050 & 222.40218 & $4.55430 \mathrm{e}-1$ & 101.28858 & Eugenitin \\
\hline 18.350 & 230.75107 & $9.76562 \mathrm{e}-4$ & $2.25343 \mathrm{e}-1$ & Genistein \\
\hline 18.838 & 204.81113 & $2.04750 \mathrm{e}-3$ & $4.19351 \mathrm{e}-1$ & Apigenin \\
\hline 19.099 & 363.45380 & $7.96178 \mathrm{e}-6$ & $2.89374 \mathrm{e}-3$ & Naringenin Chalcone \\
\hline 19.516 & 208.59067 & $1.47406 \mathrm{e}-1$ & 30.74745 & Kaempferol \\
\hline 19.952 & 114.59298 & $1.00000 \mathrm{e}-5$ & $1.14593 \mathrm{e}-3$ & Naringenin \\
\hline 20.466 & 421.15018 & $822368 \mathrm{e}-4$ & $3.46341 \mathrm{e}-1$ & Glycitein \\
\hline 21.819 & 162.15671 & $1.08600 \mathrm{e}-3$ & $1.76971 \mathrm{e}-1$ & Luteolin \\
\hline 22.600 & 266.38889 & $8.11267 \mathrm{e}-2$ & 21.61125 & Rhamnetin \\
\hline 22.853 & 98.54902 & $7.96178 \mathrm{e}-6$ & $7.84626 \mathrm{e}-4$ & Epicatechin \\
\hline 22.993 & 70.71553 & $7.96178 \mathrm{e}-6$ & $5.63022 \mathrm{e}-4$ & Epigallocatechin \\
\hline 23.470 & 128.28236 & $9.68992 \mathrm{e}-4$ & $1.34305 \mathrm{e}-1$ & Gingerol \\
\hline 23.621 & 85.01318 & $7.96178 \mathrm{e}-6$ & $6.76856 \mathrm{e}-4$ & 2-phenylethyl-beta-0-glucoside \\
\hline 23.965 & 117.02042 & $2.36563 \mathrm{e}-1$ & 27.68273 & Quercetin \\
\hline 24.185 & 138.33692 & $1.58028 \mathrm{e}-6$ & $2.18610 \mathrm{e}-4$ & Delphinidin \\
\hline 24.609 & 170.39888 & $2.97435 \mathrm{e}-2$ & 5.06826 & Isohamnetin \\
\hline 24.789 & 77.48580 & $1.60051 \mathrm{e}-6$ & $1.24017 \mathrm{e}-4$ & Malvidin \\
\hline 24.885 & 48.34124 & $3.44694 \mathrm{e}-1$ & 16.66296 & Myricetin \\
\hline 24.998 & 73.10680 & $7.961178 \mathrm{e}-6$ & $5.82061 \mathrm{e}-4$ & Pentunidin \\
\hline 25.251 & 38.96031 & $8.16993 e-8$ & $3.18303 \mathrm{e}-6$ & 3-0-caffeoylquinic \\
\hline 25.480 & 47.46246 & $1.60256 \mathrm{e}-6$ & $7.60645 e-5$ & Chlorogenic acid \\
\hline 26.291 & 57.78866 & $1.57233 \mathrm{e}-6$ & $9.08627 \mathrm{e}-5$ & Rosmarinio acid \\
\hline 26.949 & 28.27051 & $8.09585 \mathrm{e}-7$ & $2.28874 \mathrm{e}-5$ & Curcumin \\
\hline 28.192 & 18.42357 & $1.62127 \mathrm{e}-6$ & $2.98696 \mathrm{e}-5$ & Rutin \\
\hline
\end{tabular}


Table.3 Syzygium aromaticum Oil Composition using GC-FID

\begin{tabular}{|c|c|c|c|c|}
\hline Ret Time [min] & Area $\left[\mathbf{p A} *_{\mathbf{s}}\right]$ & Amount/Area & Norm \% & Name \\
\hline 6.913 & 363.18304 & $2.42438 \mathrm{e}-5$ & 1.445346 & Limonene \\
\hline 8.050 & 4.45539 & $2.91183 e-5$ & 0.021296 & Sabinene \\
\hline 10.049 & 14.64804 & $5.39835 \mathrm{e}-6$ & 0.012980 & Alpha Pinene \\
\hline 11.275 & 11.40357 & $3.75753 \mathrm{e}-6$ & 0.007034 & Beta Pinene \\
\hline 11.495 & 17.90532 & $1.39407 e-5$ & 0.040974 & Benzyl Alcohol \\
\hline 12.844 & 21.89179 & $1.34116 \mathrm{e}-6$ & 0.004820 & Cis Ocimene \\
\hline 13.031 & 57.61564 & $1.56119 \mathrm{e}-6$ & 0.014765 & Myrcene \\
\hline 13.134 & 9.60553 & $1.07742 \mathrm{e}-5$ & 0.016988 & Allo Ocimene \\
\hline 13.792 & 8.80173 & $1.71522 \mathrm{e}-5$ & 0.024782 & Pinene-2-OL \\
\hline 14.191 & 40.71996 & $2.84261 \mathrm{e}-6$ & 0.019001 & Alpha Thujene \\
\hline 14.865 & 49.16263 & $5.50605 \mathrm{e}-6$ & 0.044435 & Gama Terpinene \\
\hline 15.354 & 66.18313 & $3.30316 \mathrm{e}-6$ & 0.035886 & Neral \\
\hline 15.414 & 20.02147 & $8.51826 \mathrm{e}-6$ & 0.027996 & Geranial \\
\hline 16.331 & 41.54738 & $2.48281 \mathrm{e}-6$ & 0.016933 & Isoartemisia \\
\hline 16.738 & 206.03482 & $1.25217 \mathrm{e}-6$ & 0.042350 & 1,8-Cineole \\
\hline 17.928 & 80.16151 & $2.62150 \mathrm{e}-6$ & 0.034495 & Borneol \\
\hline 18.069 & 99.14284 & $6.85553 e-5$ & 1.115702 & Alpha-Terpinolene \\
\hline 18.195 & 207.71317 & $4.37242 \mathrm{e}-7$ & 0.014908 & Linalool \\
\hline 18.693 & 90.20630 & $1.26570 \mathrm{e}-6$ & 0.018742 & Alpha Terpineol \\
\hline 19.035 & 113.34972 & $2.63841 \mathrm{e}-6$ & 0.049092 & Terpinen-4-OL \\
\hline 19.507 & 482.86920 & $9.47419 \mathrm{e}-4$ & 75.096165 & Eugenol \\
\hline 19.813 & 134.62978 & $1.01556 \mathrm{e}-6$ & 0.022444 & Thymyl Methl Ether \\
\hline 20.580 & 268.31439 & $1.19744 \mathrm{e}-4$ & 5.274036 & Beta Caryophyllene \\
\hline 20.933 & 176.67216 & $1.07038 \mathrm{e}-6$ & 0.031042 & Linalyl Acetate \\
\hline 21.250 & 95.38912 & $2.57061 \mathrm{e}-6$ & 0.040251 & Ethyl Cinnamate \\
\hline 21.396 & 232.67856 & $2.44694 \mathrm{e}-5$ & 0.934599 & Alpha Humulene \\
\hline 21.826 & 214.76151 & $1.43639 \mathrm{e}-6$ & 0.050638 & Borneol Acetate \\
\hline 22.026 & 130.76863 & $3.67621 \mathrm{e}-6$ & 0.078913 & Phenanthrene \\
\hline 22.468 & 109.80587 & $3.35833 \mathrm{e}-7$ & 0.006053 & Linaly Acetate \\
\hline 22.823 & 96.70632 & $2.87630 \mathrm{e}-6$ & 0.045660 & Beta Bisabolene \\
\hline 23.313 & 168.88454 & $3.57345 \mathrm{e}-7$ & 0.009907 & Beta Elemene \\
\hline 24.058 & 128.40918 & $1.84824 \mathrm{e}-6$ & 0.038958 & Germacrene D \\
\hline 24.651 & 240.91310 & $8.60279 \mathrm{e}-7$ & 0.034021 & Bicyclogermacrene \\
\hline 24.862 & 117.12291 & $4.51216 \mathrm{e}-5$ & 0.867505 & Alpha Copane \\
\hline 25.542 & 116.24159 & $1.58317 \mathrm{e}-6$ & 0.030209 & Alpha Bergamotene \\
\hline 26.264 & 156.40256 & $5.28725 \mathrm{e}-4$ & 13.574370 & Acetyleugenol \\
\hline 27.128 & 49.50246 & $1.04542 \mathrm{e}-6$ & 0.008495 & Elemicin \\
\hline 27.735 & 159.33490 & $1.04539 \mathrm{e}-6$ & 0.027342 & Benzyl Benzoate \\
\hline 27.995 & 111.86918 & $4.4700 \mathrm{e}-5$ & 0.820867 & Caryophyllene Oxide \\
\hline Total $(\%)$ & & & 100.000000 & \\
\hline
\end{tabular}


Each value represents mean of three independent replicate assays and zones of inhibition were recorded to the nearest diameter in $\mathrm{mm}$ and interpreted according to Moreira et al., (2007). This implies that all test organisms are extremely sensitive to Syzygium aromaticum oil but slightly sensitive to antibacterial and antifungal drugs respectively.

$S$. aureus and $E$. coli had MIC of $5 \mu \mathrm{l} / \mathrm{ml}, P$. aeruginosa had the broadest activity of 9 $\mu 1 / \mathrm{ml}$ while MIC for all fungal isolates was 1 $\mu 1 / \mathrm{ml}$. Thus Syzygium aromaticum oil was bacteriostatic at concentrations $1 \mu \mathrm{l} / \mathrm{ml}, 5$ $\mu \mathrm{l} / \mathrm{ml}$ and $9 \mu \mathrm{l} / \mathrm{ml}$ respectively. MBC of Syzygium aromaticum oil against $S$. aureus and $E$. coli was $5 \mu \mathrm{l} / \mathrm{ml}$.

\section{Statistical Analysis}

The experimental results are presented as mean of triplicate analysis.

Essential oils are natural products that plants produce for their own needs other than nutrition (i.e. protection or attraction). Syzygium aromaticum oil was subjected to chromatographic conditions in order to achieve a proper separation of the oil components required for qualitative analysis and quantification. Ability to assay for thirtynine different compounds in Syzygium aromaticum oil (Table III) extracted through hydrodistillation method shows the effectiveness of the technique through separation of slightly volatile, waterimmiscible substances by means of low temperature distillation because most of these compounds are susceptible to decomposition at high temperature (higher than $100^{\circ} \mathrm{C}$ ).

DPPH scavenging activity assay evaluates the hydrogen-donating ability of the chainbreaking antioxidants, the antioxidants that are capable to donate hydrogen to free radicals, leading to nontoxic species and inhibition of the propagation phase of lipid oxidation. The antioxidant activity of clove extract and oil in comparison with quercetin as a scavenger of the DPPH+ radical due to reduction in these radicals (Figure I) which shows free radical scavenging characteristics exhibited by Syzygium aromaticum oil and extract thus indicates its ability to interact and neutralize free radicals, thus preventing them from causing damage. This implies that Syzygium aromaticum can be used as dietary supplements for the prevention of diseases such as cancer, coronary heart disease and even altitude sickness. Antioxidants also have many industrial uses, such as preservatives in food and cosmetics and to prevent the degradation. (Dabelstein et al., 2007).

The inhibitory activity exhibited by Syzygium aromaticum oil against the test organisms in this research is due to the presence of several constituents such as eugenol, betacaryophyllene, limonene, alpha terpinolene (Chaieb et al., 2007), acetyl eugenol, methyl salicylate, iso-eugenol, methyl-eugenol, phenylacetic acid, salicyclic acid, protocatechuic acid, p-hydroxybenzoic acid, eugenin, eugenitin (Yang et al., 2003), phenolic compounds (kaempferol, rhamnetin, isorhamnetin, myricetin, quercetin, gallic acid, caffeic acid and syringic acid) (Table II) respectively (Cai and $\mathrm{Wu}, 1996)$. The broad spectrum antimicrobial activity exhibited by Syzygium aromaticum oil and crude extract agrees with the reports of Park et al., (2007) and $\mathrm{Fu}$ et al., (2007) that reported potent antifungal and antibacterial effects of Syzygium aromaticum on microorganisms due to its mechanism of action which include denaturation of proteins and reaction with cell membrane phospholipids thus changing the membrane permeability of the microorganism. The research confirms the effectiveness of Syzygium aromaticum oil and crude extract against test organisms at varying 
inhibitory concentrations compared to antibacterial and antifungal drugs used as control. These findings justify the ethnomedicinal uses of the plant thus, represents an alternative source of natural antimicrobial substances for use in pharmaceutical industries and food system to prevent the growth of food-borne bacteria and extend the shelf-life of the processed food.

Syzygium aromaticum constituents (alkaloids, saponins, tannins and flavonoids) obtained in this research are known to have curative activity against several pathogens thus the essential oil and crude extract are hereby recommended for treatment of diseases caused by $S$. aureus, E. coli, $P$. aeruginosa and $C$. albicanss since some of these organisms are known to play a vital role in invasive skin diseases including superficial and deep follicular lesion (Usman and Osuji, 2007).

\section{References}

Adorjan, B. and G. Buchbauer 2010. Biological properties of essential oils: an updated review. J Flavour and Fragrance, 25: 407-426.

Bag, A., S.K. Bhattacharya, P. Bharati, N.K. Pal and R.R. Chattopadhyay 2009. Evaluation of antibacterial properties of Chebulic myrobalan (fruit of Terminalia chebula Retz.) extracts against methicillin resistant Staphylococcus aureus and trimethoprimsuphamethoxazole resistant uropathogenic Escherichia coli. Afri J Plant Sciences, 3: 25-29.

Burits, M. and F. Bucar 2000. Antioxidant activity of Nigella sativa essential oil. J Phytothemal Res, 14: 323.

Cai, L. and C.D. Wu. 1996. Compounds from Syzygium aromaticum possessing growth inhibitory activity against oral pathogens. J Natural Products, 59: 987990.

Chaieb, K., H. Hajlaoui, T. Zmantar, K.A.B. Nakbi, M. Rouabhia, K. Mahdouani and A. Bakhrouf. 2007. The chemical composition and biological activity of essential oil, Eugenia cryophyllata (Syzygium aromaticum L. Myrtaceae): a short review. J Phytothermal Res, 21(6): 501-506.

Dabelstein, W., A. Reglitzky, A. Schütze, and K. Reders. 2007. "Automotive Fuels". "Ullmann's Encyclopedia of Industrial Chemistry".

Fiori, A.C.G., K.R.F. Schwan - Estrada, J.R. Stangarlin, J.B. Vida, C.A. Scapim, M.E.S. Guz and S.F. Pascholti, S.F. 2000. Antifungal Activity of Leaf Extracts and Essential Oils of some Medicianal Plants against Didymella bryonial. J Phytopathology, 148: 483.

Fu, Y., Y. Zu, L. Chen, X. Shi, Z. Wang, S. Sun and T. Efferth. 2007. Antimicrobial activity of clove and rosemary essential oils alone and in combination. J Phytothermal Res. 21(10): 989-994.

Hammer, K.A., C.F. Carson, and T.V. Riley. 1996. Susceptibility of transient and commensal skin flora to the essential oil of Melaleuca alternifolia (tea tree oil). American J Infection Control 24: 186189.

Jonathan, S.G. and I.O. Fasidi. 2003. An Original Article on Antimicrobial activities of two Nigerian Edible macrofungi Lycoperdon pusilum and Lycoperdon giganteum. Afri $\mathbf{J}$ Biomedical Research 6: 85-90.

Kelley, W.T., D.L. Coffey and T.C Mueller. 1994. Liquid chromatographic determination of phenolic acids in soil. AOAC; 77:805-809.

Khokra, S.L., O. Prakash, S. Jain, K.R. Aneja and Y. Dhingra. 2008. Essential oil composition and antibacterial studies of 
Vitex negundo Linn. Extracts. Indian J Pharm Sci, 70: 522-526.

Lee, S.J., J.L. Han, G.S. Lee, M.J. Park, I.G. Choi, K.J. Na and E.B. Jeung. 2007. Antifungal effect of eugenol and nerolidol against Microsporum gypseum in a guinea pig model. J Biol. Pharm., 30:184-188.

Moreira, R., G.P. Alejandra, E.D.V. Carlos and R. Sarai. 2007. Effects of clove and tea tree oils on Escherichia coli O157:H7 in cooked beef. J Food Process Preservation, 31(4): 379-391.

Okeke, M.I., C.U. Iroegbu, E.N. Eze, A.S Okoli and C.O. Esimone. 2001. Evaluation of extracts of the root of Landolphia owerrience for antibacterial activity. J Ethnopharm, 78: 119-127.

Park, M.J., K.S. Gwak, I. Yang, W.S. Choi, H.J. Jo, W.J. Chang, E.B. Jeung and I.G. Choi, 2007. Antifungal activities of the essential oils in Syzygium aromaticum (L.) Merr. Et Perry and Leptospermum betersonni Bailey and their constituents against various dermatophytes. J Microbio, 45: 460465.

Provan, G.J., L. Scobbie and A. Chesson. 1994. Determination of phenolic acids in plant cell walls by microwave digestion. J Sci Food Agric, 64:63-65.

Schnaubelt, K. 2005. Essential oil therapy according to Chinese medical concepts. Inter J Aroma, 15(2):98-105.

Skold, M., L. Hagvall, and A.T. Karlberg. 2008. Autoxidation of linalyl acetate, the main compound of lavender oil, creates potent contact allergens. J Contact Dermatitis, 58: 9-14.

Sofowora, A. 1993. Medicinal plants and traditional medicine in Africa. 2nd Ed. Sunshine House, Ibadan, Nigeria: Spectrum Books Limited. Screening Plants for Bioactive Agents. pp. 134156.

Trongtokit, Y., Y. Rongsriyan, N. Komalamisra and L. Apiwathnasom. 2005. Comparative repellency of 38 essential oils against mosquito bites. Phytothermal. Res., 19(4): 303-309.

Usman, H. and J.C. Osuji 2007. Phytochemical and in vitro antimicrobial assay of the leaf extract of Newbouldia leavis. Afri J Trad, Complem Alter Medicines, 4(4):476480.

Viuda-Martos, M., Y. Ruíz-Navajas, J. Fernández-López and J.A. PérezÁlvarez. 2007. Chemical Composition of the Essential Oils Obtained From Some Spices Widely Used in Mediterranean Region. Acta Chim. Slov, 54, 921-926.

Yang, Y.C., S.H. Lee, W.J. Lee, D.H. Choi and Y.J. Ahn. 2003. Ovicidal and adulticidal effects of Eugenia cryophyllata bud and leaf oil compounds on Pediculus capitis. J Agric Food Chem, 51(17): 4884-4888.

\section{How to cite this article:}

Simiat Olanike Jimoh, Lateefah Adelanke Arowolo and Kazeem Adelani Alabi. 2017. Phytochemical Screening and Antimicrobial Evaluation of Syzygium aromaticum Extract and Essential oil. Int.J.Curr.Microbiol.App.Sci. 6(7): 4557-4567.

doi: https://doi.org/10.20546/ijcmas.2017.607.476 